library shelves is wide, encompassing all aspects of catalysis with the emphasis on phenomena connected with industrial catalysts and processes.

Applied Catalysis accepts full papers, short communications and even correspondence. In fact, though, all material published so far appears to be in the first category, and almost all of it is devoted to some aspect of heterogeneous catalysis. The scientific standard is high, and the content and style of the contributions is very similar to those that appear in the Journal of Catalysis.

I would guess that Applied Catalysis was conceived out of the frustration that many authors have felt with the older journal over its very long publication times. So a major aim of the editors is to offer rapid publication which it is hoped will be achieved by using camera-ready copy. This has been partially successful with papers appearing in print about six months after submission. However, as is the case with other journals devoted to catalysis, the acceptance time seems unnecessarily long, being generally at least two months.

An interesting feature is a "News Brief" section collated by J.R.H. Ross from a team of 25 international correspondents who sometimes seem uncertain whether they are writing for Transactions of the Faraday Society or for Chemical and Engineering News. Nevertheless it manages to be entertaining and educational, containing titbits of information on such things as industrial catalyst supports, grants, forthcoming events, excellent book reviews, and even a description of a device for heating shaving foam as it leaves the dispenser.

Applied Catalysis already has a secure readership and has developed into a serious competitor for the Journal of Catalysis. Its success can be measured by the fact that although it was originally published as one volume of six issues costing $\$ 88.75$, in 1982 the intention is to publish three volumes of four issues costing $\$ 200.75$. This is at once a sign of good health and an omen for librarians; be warned, if this trend continues it could rival its sister publication the Journal of Organometallic Chemistry, now published at the rate of one a week and costing more than $\$ 1,000$ per annum.

L1

David J.H. Smith, presently on secondment to the British Petroleum Research Centre, Sunbury, Middlesex, is a Lecturer in Chemistry at Leicester University.

\title{
On the right track?
}

\section{David Briggs}

TRAC (Trends in Analytical Chemistry). Editor P.T. Shepherd. 12/yr. (Elsevier Scientific.) $£ 22$ UK, $\$ 40$ North America, Dfl.105 Europe (personal); Dfl.320 UK, North America and Europe, Dfl.334 elsewhere (institutional + compendium).

THE stated aim of Trends in Analytical Chemistry is

to promote an awareness of the latest trends and developments in analytical chemistry, not only amongst analytical chemists themselves, but amongst all those who use or must be familiar with analytical methods.

The style is that of a magazine with short articles of the news/comment/interest/ review type, together with about five (invited) review papers, each on average no more than five pages in length. Each issue is therefore rather thin. The presentation is clear but there is no standardization of the style of figures or illustrations. Cartoons are occasionally included, even in the reviews, presumably to lighten the reading matter. This feature, however, is apparently to be dropped.

It is difficult to believe that the gap which the publishers of TRAC are hoping to fill that for a general awareness bulletin really exists. Analytical chemistry is a wide field and has several well-developed branches such as spectroscopy, chromatography and chemical assay. Most professional analytical chemists are specialists either in one of these branches or in a particular field of application, both types already being well served by primary and review literature sources. Many, if not most, of the reviews in TRAC merely duplicate this material.

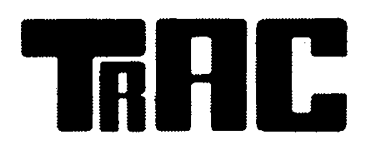

On the other hand, the journal Analytical Chemistry still manages to straddle the field and does an admirable job of providing regular "trend" reviews. There are also a number of publications which provide general awareness information for the non-specialist, including the plethora of free bulletins produced by the instrument manufacturers.

In principle there might be a place for TRAC in the mail-boxes of personal subscribers, but when compared with the alternative sources it does not seem to offer value for money. On the basis of existing evidence, then, it is hard to see that $T_{R} A C$ is making any significant addition to the literature currently available.

David Briggs is in the Petrochemicals and Plastics Division of ICI, Welwyn Garden City, Hertfordshire.

\section{Mixed STS}

\section{Russell Moseley}

Bulletin of Science, Technology and Society. Editor-in-chief Rustum Roy. 6/yr. (Pergamon.) £42.50, \$48.50.

FOR some years now the area of study known as science, technology and society has been catered for by such journals as Social Studies of Science, Research Policy, Radical Science Journal and Science and Public Policy. This is not to mention the orthodox history and philosophy of science publications, and such journals as Minerva, Studies in Science Education and the like. Why, then, is there felt to be a need for yet another publication in this field?

Most obligingly the editors of the Bulletin of Science, Technology and Society (BSTS) list a number of reasons: the journal provides a place where shorter papers on science studies can be published rapidly; it aims to become the principal house journal of the emerging science studies community; and it publishes a wide range of educational modules designed specifically for teaching purposes. In this last respect BSTS is, as the editors point out, something of an innovation being a hybrid between a textbook and a journal. It could of course equally well be seen as neither a textbook nor a journal.

The success of BSTS in meeting its stated aims is, on the basis of Vol. 1, patchy at best. It has certainly succeeded in publishing shorter papers (only two of which are by authors who are not members of the editorial board) on a wide range of topics, although these comprise only 20 per cent of the whole of Vol. 1. Even less space is devoted to "News and Reviews" (less than 4 per cent of the first volume), and the editors' hope that "lively debate among authors and readers" will occur is, on the available evidence, unlikely to be realized: the first six issues contain not a single letter from a reader.

On the other hand the ample provision of educational material has certainly been accomplished, and has possibly been carried to excess: no less than 77 per cent of Vol. 1 is composed of reprinted course units which are intended to be used for educational purposes. Much of this material has been available for some time and it is debateable whether subscribing to BSTS is the most cost-effective way of building up a collection.

Does the journal fill a gap? To an extent it does by operating at a more popular, accessible level than some of the competing publications. But its hybrid form means it is in danger of slipping through the gap and disappearing. I hope it develops a more tenacious hold in subsequent volumes.

Russell Moseley is Assistant Registrar for Science with the Council for National Academic Awards, London. 